\title{
Effects of Bicultural Identity Integration and National Identity on COVID-19-Related Anxiety Among Ethnic Minority College Students: The Mediation Role of Power Values
}

This article was published in the following Dove Press journal:

Psychology Research and Behavior Management

\section{Yan Long (iD) ${ }^{1,2}$ \\ Fangying Quan ${ }^{3}$ \\ Yong Zheng (iD) 4 \\ 'Center for Studies of Education and Psychology of Ethnic Minorities in Southwest China, Southwest University, Chongqing, People's Republic of China; ${ }^{2}$ Department of Student Affairs, Guilin Tourism University, Guilin, People's Republic of China; ${ }^{3}$ Faculty of Education, Guangxi Normal University, Guilin, People's Republic of China; ${ }^{4}$ Faculty of Psychology, Southwest University, Chongqing, People's Republic of China}

\section{Video Abstract}

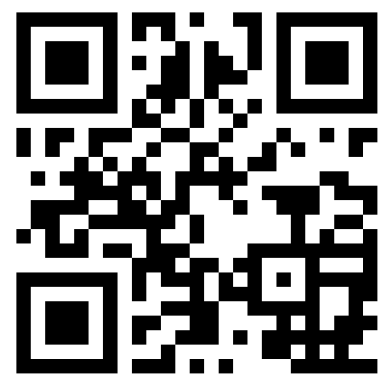

Point your SmartPhone at the code above. If you have a $Q R$ code reader, the video abstract will appear. Or use: https://youtu.be/laeVJTXkY2C
Correspondence: Yong Zheng

Faculty of Psychology, Southwest

University, Chongqing, 4007I5, People's

Republic of China

$\mathrm{Tel}+8613667636167$

Email zhengy@swu.edu.cn
Purpose: The current study investigated the association between bicultural identity integration (BII, incorporating BII-harmony and BII-blendedness), national identity, and anxiety related to Coronavirus disease 2019 (COVID-19) among ethnic minority college students. In addition, this research examined the mediation role of power values in the relationship between BII, national identity, and COVID-19-related anxiety.

Methods: This cross-sectional research design made use of online surveys. Using convenience sampling, participants comprised 235 Chinese ethnic minority college students drawn from four colleges in the ethnic minority autonomous regions of China. Data were collected during June 2020. Participants mainly lived in ethnic minority communities or villages in southwest China before receiving higher education at urban campuses.

Results: Correlation analysis revealed that BII-harmony, BII-blendedness, and national identity were significantly negatively correlated with COVID-19-related anxiety. Mediation model analysis showed that power values were significantly positively correlated with COVID-19-related anxiety. Power values play a mediating role in the relationship between BII-harmony, national identity, and COVID-19-related anxiety, and have an inhibitory effect on this relationship.

Conclusion: Our findings indicate that BII-harmony and national identity could have the function of protecting ethnic minority college students from COVID-19-related anxiety. Emphasizing individualistic personal power values could increase COVID-19-related anxiety, whereas a collectivist identity reduces anxiety. These findings could provide another perspective on psychological interventions to reduce anxiety during the COVID-19 pandemic.

Keywords: bicultural identity integration, national identity, power values, COVID-19related anxiety, ethnic minority college students

\section{Introduction}

The COVID-19 outbreak was officially classified as a pandemic by the World Health Organization in March 2020. The pandemic has resulted in a high prevalence of stress and anxiety, which has had a negative psychological and social impact on people globally. ${ }^{1}$ An increasing number of studies have focused on the psychological state of the public and resilience during the COVID-19 epidemic. ${ }^{1-3}$ For people in the most affected regions, COVID-19 has been a source of stress and 
a trigger for anxiety. ${ }^{4}$ COVID-19-related anxiety is thus a highly relevant topic worth investigating. Students across the world are also at risk of COVID-19-related mental health problems due to concerns about their future and academic progress. Understanding the cultural psychological factors involved in COVID-19-related anxiety is important because for some people these factors lead to clinically significant anxiety. ${ }^{5}$

With regard to the COVID-19 crisis, one study found that $6.3 \%$ of Chinese people suffered from anxiety. ${ }^{6}$ Another study involving Chinese participants of health care workers found that $44.6 \%$ had anxiety. ${ }^{7}$ In terms of cultural factors associated with the public's response to COVID-19, collectivism is positively associated with efforts to reduce the spread of COVID- $19 .{ }^{8}$ China is a country with a typically collectivist culture, which is more obvious in the country's ethnic minority areas. The Chinese poet Fan Zhongyan famously wrote, "Before the world's sorrow and sorrow, after the world's joy and joy," reflecting the collectivist value orientation advocated by the Chinese people which puts the interests of the country and the collective first. The pursuit of stability and peace in life still influences the mentality of Chinese people today. At the same time, the Chinese believe that hardship and even death can be an opportunity for development and renewal. Rather than indulge in a grievance complex, Chinese people prefer to fight the battle to the maximum extent possible with the strength of the collective, in other words, a kind of collective heroism. ${ }^{9}$ Compared with their Western counterparts, Chinese people have shown more positive emotions in the face of the COVID-19 disaster. ${ }^{10}$ It is possible that collectivists could gain a sense of power in the face of difficulties that require collective effort; In contrast, individualists may be less likely to exploit this power. ${ }^{8}$ Therefore, it is possible that cultural identity and power values may help explain the difference in individualists' and collectivists' reactions to COVID-19. Individualists are unlikely to feel the power of collective support, making their individual contributions less meaningful. In an individualistic culture, national identity is associated with more individualistic values, whereas in a collectivist culture, is associated with more altruistic values. ${ }^{11}$ This suggests that bicultural identity integration and national identity are characteristic of China's collectivist culture. Therefore, understanding the cultural factors that influence people's anxiety responses to the COVID19 epidemic is important. Here, we investigated the influence of BII-harmony and national identity among China's ethnic minority college students on COVID-19 related anxiety and explored the mediating role of personal values.

\section{Bicultural Identity Integration and COVID-19-Related Anxiety}

Culture shapes the way people understand difficulties. In fact, providing guidance and comfort in the face of suffering is one of the main roles of a cultural worldview. ${ }^{12}$ Cultural psychology has paid particular attention to ethnic cultural identity and psychological and behavioral adaptation. ${ }^{13,14}$ Berry's acculturation strategy model proposed types and advantages of acculturation. ${ }^{15}$ Cultural identity has been linked to positive mental health and psychosocial function in ethnic minority adolescents, and acts as a buffer against the deleterious consequences of adverse life events. ${ }^{16-18}$ In addition, it is related to lower levels of mental health problems among adolescents, ${ }^{19,20}$ is protective for mental health concerns, ${ }^{21,22}$ and improves adolescent well-being as evidenced by less daily anxiety ${ }^{23}$ and fewer depressive symptoms. ${ }^{24-27}$

The mental health of ethnic minority members has been a long-term concern in China. Generally, ethnic minorities have their own language, religion, and costumes. Nowadays, due to the need for higher education, ethnic minority adolescents who grew up in ethnic minority communities, such as the ethnic minority villages in southwest China, attend urban campuses and blend in with the Han culture. Chinese college students from minority ethnic groups also experience multicultural amalgamation in a distinct context. ${ }^{28}$ When ethnic minorities move from their original culture, which they are familiar with, to the Han culture, they may encounter acculturation problems caused by cultural shock. The acculturation process may be associated with stress as the individual strives to achieve a balance between cultures, known as acculturative stress. ${ }^{15}$ Ethnic minority college students often suffer greater psychological disturbance than do their native peers. Therefore, to develop prevention strategies aimed at mitigating the risk of mental disorders in multicultural communities, research on cultural identity and acculturation is necessary. ${ }^{29,30}$ For minority college students, the degree of integration of bicultural identity and national identity are the manifestations of acculturation.

BII is a variable that has been found to relate a person's anxiety. BII significantly negatively related acculturative stress. ${ }^{31}$ BII refers to the manner in which individuals deal 
with the divides and connections between their own minority culture and the dominant culture. ${ }^{32}$ In other words, BII is a construct used to describe a bicultural individual's thoughts and feelings about the intersection of their ethnic and mainstream cultural orientations. ${ }^{33}$ There are two independent components in BII: cultural harmony (BIIharmony, as opposed to conflict), and cultural blendedness (BII-blendedness, as opposed to compartmentalization), Bicultural Identity Integration Scale-Version 2 (BIIS-2) is a stable and reliable scale and has been widely used. ${ }^{34}$ High BII individuals consider their two identities to be compatible (ie bicultural harmony), and think of themselves as belonging to a hyphenated (or hybrid) culture. In contrast, individuals with low BII struggle to balance these two identities (ie bicultural conflict), and are constantly compartmentalizing their cultures. This kind of cultural identity describes the process of identity in a multicultural world, and it is considered to be more consistently and closely associated with mental health compared with national or ethnic identities. ${ }^{35}$ The cultural distance between origin and destination culture is positively related to the difficulty of adaptation for immigrants and, consequently, associated with lower well-being in these individuals. ${ }^{36}$ Therefore, we can speculate that BII is associates with anxiety through reviewing the following ideas and research.

First, BII is closely associated with psychological health. $^{37}$ BII-harmony was positively associated with improving psychological health ${ }^{38}$ and reducing depressive symptoms in bicultural undergraduates. ${ }^{34}$ Scholars have begun to examine differences in individual experiences of biculturalism and psychological health. ${ }^{39}$ In addition, BII is also associated with psychological adjustment, which includes increased positive emotionality, life satisfaction, decreased feelings of anxiety. ${ }^{39-41}$ For example, individuals with high BII are often correlated with more favorable behavioral and psychological adjustment levels. ${ }^{42}$ Accordingly, individuals with high BII may associate with lower anxiety levels. Thus, we propose hypothesis one: BII is associates with COVID-19-related anxiety.

\section{National Identity and COVID-19-Related Anxiety}

National identity is described as an individual's feeling of belonging within a larger society. ${ }^{43}$ It includes a person's national pride and positive feelings about their cultural background and attachment to their ethnic minorities. ${ }^{44}$
National identity refers to individuals' psychological affiliation with the country in which they currently reside. $^{45,46}$ A strong sense of national identity is often thought of as a positive psychological trait. ${ }^{47}$

Several studies have provided evidence for this view. For example, national identity improved the belief in political institutions during a crisis in Brazil. ${ }^{48}$ Furthermore, ethnic identity is positively correlated with mental health. ${ }^{35}$ The components of ethnic and national identity and strong ethnic and national collective self-esteem were associated with lower levels of anxiety among AsianAmerican adolescents. ${ }^{49}$ positively correlated to social connectedness, ${ }^{50}$ associated with a more positive attitude toward interethnic contact, ${ }^{51}$ and was assumed to buffer against distress. $^{52}$ In addition, strong ethnic identity is related to the reduction of depressive symptoms ${ }^{53}$ and to the reduction of perceived stress among ethnic minority immigrants. ${ }^{54}$ Thus, we propose hypothesis two: National identity is associates with COVID-19-related anxiety.

China is a multiethnic country. In the Chinese context, national identity refers to one's sense of Chinese identity. BII is positively correlated with national identity and ethnic identification. For instance, one study found that identification with either American culture or with ethnic culture were both significantly and positively associated with BII. ${ }^{55}$ Another study of international transracial adoptees also found that a strong BII was significantly related to a solid identification with both national and ethnic identities. ${ }^{56}$ Therefore, it is implied that individuals with a high level of BII-harmony will also possess stronger national or ethnic identities. Thus, we propose hypothesis three: BII-harmony is associates with COVID-19-related anxiety.

\section{Power Values as Mediators}

We postulate that power values mediate the relationship between BII-harmony, national identity and COVID-19related anxiety. Values emphasizing power remain one of the most important core values for many Chinese people. ${ }^{57}$ Values are particularly suitable for researching the motivational essence of individual differences in national and ethnic culture identification. ${ }^{58}$ According to social identity researchers, each ethnic community has its own set of unique values, group norms, attitudes, and behaviors. ${ }^{59}$ Schwartz (1992) developed a theory of the structure of human values, containing ten universal values. ${ }^{60}$ The model of power values suggests three potential subtypes: the dominance subtype, which involves the control of 
others (social power); the resources subtype, which includes the control of material resources (wealth/material possessions); the face subtype, which emphasizes social respect, maintenance of the public image, preserving the image and prestige. ${ }^{61}$ Values emphasizing power positively associate with depressive symptoms and hopelessness. $^{62}$ People who strongly emphasize "extrinsic" instead of "intrinsic" life goals or personal strivings experience higher anxiety, depression, and physical symptoms. ${ }^{63}$ Therefore, it is implied that individuals with a high level of power values will also be subject to higher levels of COVID-19-related anxiety.

In addition, we propose that BII-harmony is negatively associated with power values. First, self-enhancement values include power and achievement, are positively related with exclusionism, and negatively associated with integration. ${ }^{64}$ Further, power values are positively related to individualism (individualism is the opposite of integrationism and suggests self-enhancement). This implies that BII-harmony negatively relates predicts power values. Thus, we propose hypothesis four: Power values mediate the relationship between BII-harmony and COVID-19related anxiety.

Finally, studies that have examined national identification found it correlated positively with power values in America and negatively with power values in Israel. ${ }^{65}$ Self-enhancement correlated negatively with power values in China. ${ }^{51}$ Thus, we propose hypotheses five: Power values play a mediating role in the relationship between national identity and COVID-19-related anxiety.

\section{Materials and Methods}

\section{Participants}

For this study, 235 college students (98 male, 137 female) were recruited from the Guangxi Zhuang autonomous minority ethnic region in China (They have lived mainly in ethnic minority communities before going to college, $\mathrm{M}_{\text {age }}$ $=20.56, \mathrm{SD}=1.55)$. The ethnic minorities mainly included people of Zhuang, Yao, Yi, Miao, and Dong background. The study displays the ethnic composition of the samples in Table 1. Participants were selected on the basis that they had grown up in an area inhabited by ethnic minorities before receiving higher education and were native speakers. We balanced the subjects' ethnicity and sex. Data were collected in June 2020, by when people in China had returned to work and production following the initial lockdown. The college students in this study had been back on campus for an
Table I Ethnic Composition of the Samples

\begin{tabular}{|l|c|c|c|c|c|c|}
\hline \multirow{2}{*}{ Ethnic } & \multicolumn{4}{|c|}{ Gender } & \multicolumn{2}{c|}{ Overall } \\
\cline { 2 - 5 } & \multicolumn{2}{|c|}{ Male (n=98) } & \multicolumn{2}{c|}{ Female (n=137) } & \multicolumn{2}{c|}{} \\
\cline { 2 - 5 } & Count & $\%$ & Count & $\%$ & Count & $\%$ \\
\hline Zhuang & 18 & $18.4 \%$ & 24 & $17.5 \%$ & 42 & $17.9 \%$ \\
Yao & 10 & $10.2 \%$ & 17 & $12.4 \%$ & 27 & $11.5 \%$ \\
Miao & 14 & $14.3 \%$ & 11 & $8.0 \%$ & 25 & $10.6 \%$ \\
Yi & 9 & $9.2 \%$ & 13 & $9.5 \%$ & 22 & $9.4 \%$ \\
Dong & 7 & $7.1 \%$ & 11 & $8.0 \%$ & 18 & $7.7 \%$ \\
Mulam & 6 & $6.1 \%$ & 9 & $6.6 \%$ & 15 & $6.4 \%$ \\
Manchu & 4 & $4.1 \%$ & 10 & $7.3 \%$ & 14 & $6.0 \%$ \\
Tibetan & 5 & $5.1 \%$ & 7 & $5.1 \%$ & 12 & $5.1 \%$ \\
Mongol & 4 & $4.1 \%$ & 7 & $5.1 \%$ & 11 & $4.7 \%$ \\
Li & 6 & $6.1 \%$ & 4 & $2.9 \%$ & 10 & $4.3 \%$ \\
Hui & 5 & $5.1 \%$ & 4 & $2.9 \%$ & 9 & $3.8 \%$ \\
Buyi & 2 & $2.0 \%$ & 5 & $3.6 \%$ & 7 & $3.0 \%$ \\
Uighur & 2 & $2.0 \%$ & 4 & $2.9 \%$ & 6 & $2.6 \%$ \\
Tujia & 3 & $3.1 \%$ & 2 & $1.5 \%$ & 5 & $2.1 \%$ \\
Shui & 1 & $1.0 \%$ & 4 & $2.9 \%$ & 5 & $2.1 \%$ \\
Maonan & 2 & $2.0 \%$ & 1 & $0.7 \%$ & 3 & $1.3 \%$ \\
Dai & 0 & 0 & 2 & $1.5 \%$ & 2 & $0.9 \%$ \\
Jing & 0 & 0 & 2 & $1.5 \%$ & 2 & $0.9 \%$ \\
\hline
\end{tabular}

average of one month. We collected the data via a Chinese online survey platform. The participants received a $¥ 10$ reward at the end of the survey.

\section{Procedure}

The present study was approved by the ethics committee of the Faculty of Psychology at Southwest University, China. This cross-sectional research design used convenience sampling and online surveys. Prior to participating in the study, participants were informed that the questionnaire was completely anonymous, only the researcher has access to the data collected, and the data collected would be used only for academic research. Further, informed consent was obtained online. This study was conducted in accordance with the Declaration of Helsinki.

\section{Measures}

Measurement of Bicultural Identity Integration

The 19-item BIIS-2 was used to measure BII. ${ }^{34}$ Items were rated from 1 (strongly disagree) to 7 (strongly agree). Example items include, "I rarely feel conflicted about being bicultural" and "I find it difficult to combine my ethnic and national cultures." The BIIS-2 contains two separate scores: cultural harmony and cultural blendedness. 
Higher scores of cultural harmony reflect more harmony (or less conflict); higher scores of cultural blendedness reflect more integration (or less compartmentalization). The factor structure of BII is acceptable and has good discriminant and convergent validities. ${ }^{35}$ In the preparation processes of the BII-2 questionnaire and subsequent studies, it has been found that it has good cross-cultural reliability. ${ }^{55}$ Additionally, in a specifically Chinese study, the BIIS-2 also showed good reliability. ${ }^{66}$ In the current sample, internal consistency of BIIS-2 was adequate; Cronbach's alpha was 0.68 for BII-harmony, and 0.65 for BII-blendedness in this study.

\section{Measurement of National Identity}

We used the 19-item National Identity Questionnaire ${ }^{67}$ to measure each participant's sense of national identity. Examples of the items include "I am proud of being Chinese" and "I know some legends and symbols of the Chinese nation (such as the dragon)". Items were rated on a scale ranging from 1 (strongly inconsistent) to 6 (strongly consistent), with higher scores denoting a stronger sense of national identity. The Cronbach's alpha for this scale was 0.89 in this study.

\section{Measurement of Power Values}

Power values were measured using items from the Portrait Values Questionnaire (PVQ-57), ${ }^{61}$ which has been widely used in international research into values. The items in PVQ describe one's values. Participants were asked to rate items such as "How much is this person like you" on a scale ranging from 1 (not like me at all) to 6 (very much like me). Power values was one of the 10 original value types, including the subtypes of power dominance, power resources, and face. The original questionnaire has been previously validated in Chinese. The Cronbach's alpha of the power values scale was 0.75 .

\section{Measurement of COVID-19-Related Anxiety}

Anxiety around the pandemic was measured using items adapted from the 4-item COVID-19-related anxiety scale developed by Killgore et al (2020). ${ }^{68}$ The items include, "Since the outbreak, I feel scared about the future," "I have a persistent deep sense of dread from this crisis," and "I worry about how this crisis is affecting my mental health." Items were rated on a scale ranging from 1 (strongly inconsistent) to 7 (strongly consistent); the higher scores, the greater COVID-19-related anxiety. In this study, the Cronbach's alpha for this scale was 0.89 .
Confirmatory factor analysis shows that the fit index of the fitness index scores of the model are as follows: $\chi^{2}=$ 443.10, TLI $=0.99, \mathrm{CFI}=0.997, \mathrm{SRMR}=0.008$, RMSEA $=0.037$.

\section{Statistical Analyses}

Date were analyzed using SPSS 23.0, Mplus 7.0, and AMOS 23.0 software programs (IBM Corporation, New York, USA). First, the confirmatory factor analysis was examined by Mplus 7.0. Second, the study applied descriptive statistics and correlation analysis by SPSS 23.0. We applied independent $t$-tests to compare sex groups for our study variables. Third, we used AMOS 23.0 to test structural equation models.

\section{Results}

\section{Common-Method Bias Test}

In this study, Harman's single factor method was applied to test the common-method bias. ${ }^{69}$ The results suggest that the first common variance factor was $18.10 \%$, which was lower than the critical criterion $(40 \%)$. There was no obvious co-method bias in this study.

\section{Preliminary Analyses}

SPSS 23.0 software was applied on descriptive statistics, $t$-test and correlation analysis.

Anxiety was rated on a 7-point Likert-type scale. Table 2 shows the average values of each item. According to the total mean value, $18.30 \%$ of participants reported almost no anxiety $(\mathrm{M}=1-1.5), 38.7 \%$ participants reported mild anxiety $(\mathrm{M}=1.75-3.5), 34.90 \%$ of participants reported moderate levels of anxiety $(\mathrm{M}=$ $3.75-5.5)$, and $8.1 \%$ of participants reported high levels of anxiety $(\mathrm{M}=5.75-7)$.

Table 3, displays the results of the $t$-test analyses, no significant differences in sex were found between BIIharmony, BII-blendedness, national identity, power values, and anxiety. Table 4, displays the results of the partial Pearson's correlation analyses. As expected, there were significantly negative relationships between BII-harmony and BII-blendedness with COVID-19-related anxiety, with both being negatively correlated with power values. A significantly negative relationship was found between national identity and COVID-19-related anxiety, and national identity and power values. Power values was positively correlated with anxiety about the effects of COVID-19. 
Table 2 Descriptive Statistics of Anxiety Items

\begin{tabular}{|c|c|c|c|c|c|c|c|c|}
\hline \multirow[t]{2}{*}{ Rate } & \multicolumn{2}{|c|}{ Item I } & \multicolumn{2}{|c|}{ Item 2} & \multicolumn{2}{|c|}{ Item 3} & \multicolumn{2}{|c|}{ Item 4} \\
\hline & Freq & $\%$ & Freq & $\%$ & Freq & $\%$ & Freq & $\%$ \\
\hline I & 63 & 26.8 & 54 & 23.0 & 60 & 25.5 & 62 & 26.4 \\
\hline 2 & 31 & 13.2 & 33 & 14.0 & 36 & 15.3 & $4 I$ & 17.4 \\
\hline 3 & 24 & 10.2 & 25 & 10.6 & 38 & 16.2 & 32 & 13.6 \\
\hline 4 & 35 & 14.9 & 52 & 22.1 & 36 & 15.3 & 39 & 16.6 \\
\hline 5 & 39 & 16.6 & 37 & 15.7 & 34 & 14.5 & 33 & 14.0 \\
\hline 6 & 21 & 8.9 & 14 & 6.0 & 16 & 6.8 & 11 & 4.7 \\
\hline 7 & 22 & 9.4 & 20 & 8.5 & 15 & 6.4 & 17 & 7.2 \\
\hline $\mathrm{M} \pm \mathrm{SD}$ & \multicolumn{2}{|c|}{$3.46 \pm 2.03$} & \multicolumn{2}{|c|}{$3.46 \pm 1.90$} & \multicolumn{2}{|c|}{$3.24 \pm 1.87$} & \multicolumn{2}{|c|}{$3.17 \pm 1.88$} \\
\hline
\end{tabular}

Notes: $\mathrm{n}=235$, Item I: I fear we will never be free of COVID-19; Item 2: I have a persistent deep sense of dread from this crisis; Item 3: Since the outbreak, I feel scared about the future; Item 4: I worry about how this crisis is affecting my mental health. Rate I-7: strongly inconsistent to 7 strongly consistent.

Abbreviation: Freq, frequency.

Table $3 t$-Test in Sex Between Bll-Harmony, Bll-Blendedness, National Identity, Power Values, and Anxiety

\begin{tabular}{|l|c|c|c|c|c|c|}
\hline & \multicolumn{2}{|c|}{$\begin{array}{c}\text { Male } \\
\text { (N=98) }\end{array}$} & \multicolumn{2}{c|}{$\begin{array}{c}\text { Female } \\
(\mathbf{N}=137)\end{array}$} & t & P \\
\cline { 1 - 5 } & Mean & SD & Mean & SD & & \\
\hline I. Bll harmony & 4.62 & 0.61 & 4.61 & 0.57 & 0.24 & 0.81 \\
\hline 2. Bll blendedness & 4.84 & 0.88 & 4.68 & 0.79 & 1.46 & 1.50 \\
\hline 3. National identity & 5.24 & 0.57 & 5.27 & 0.59 & -0.40 & 0.69 \\
\hline 4. Power & 4.43 & 0.80 & 4.25 & 0.68 & 1.89 & 0.06 \\
\hline 5. Anxiety & 3.39 & 1.81 & 3.29 & 1.51 & 0.42 & 0.68 \\
\hline
\end{tabular}

\section{Mediation Analysis}

Based on our preliminary analysis, we conducted a mediation analysis to determine whether the prediction of BII and national identity on COVID-19-related anxiety was mediated by power values. We used 5000 bootstrapping re-samples procedures to test the significance of the mediation effects of power values, and $95 \%$ confidence interval (CI) was calculated.

The analysis results demonstrated that there was no significant effect of BII-blendedness on COVID-19related anxiety and power values $(\mathrm{P}>0.05)$. Therefore, we only analyzed BII-harmony in the model. The results are shown in Table 5. The total indirect effect of power values in the relationship between BII-harmony, national identity, and COVID-19-related anxiety was statistically significant. The study's mediation model is demonstrated in Figure 1.

Figure 1 demonstrates the findings of the tested mediation of power values in the relationship between BIIharmony, national identity, and COVID-19-related anxiety. In the model, BII-harmony and national identity were

Table 4 Correlations Between BII, National Identity, Power Values, COVID-19-Related Anxiety

\begin{tabular}{|l|l|l|l|l|l|l|}
\hline & Mean & SD & I & $\mathbf{2}$ & $\mathbf{3}$ & $\mathbf{4}$ \\
\hline I. BII harmony & $4.6 \mathrm{I}$ & 0.59 & $\mathrm{I}$ & & \\
\hline 2. BII blendedness & 4.75 & 0.83 & $0.44^{* * *}$ & $\mathrm{I}$ & \\
\hline 3. National identity & 5.26 & 0.58 & $0.32^{* * *}$ & $0.35^{* * *}$ & $\mathrm{I}$ & \\
\hline 4. Power & 4.32 & 0.74 & $-0.21^{* *}$ & $-0.21^{* *}$ & $-0.27^{* * *}$ & I \\
\hline 5. Anxiety & 3.33 & 1.64 & $-0.30^{* * *}$ & $-0.22^{* *}$ & $-0.26^{* * *}$ & $-0.23^{* * *}$ \\
\hline
\end{tabular}

Notes: $\mathrm{n}=235,{ }^{* *} \mathrm{p}<0.01$, **** $p<0.001$. 
Table 5 Bootstrapping Indirect Effects and 95\% Confidence Intervals $(\mathrm{Cl})$ for the Mediation Model

\begin{tabular}{|l|c|c|c|}
\hline $\begin{array}{l}\text { Model } \\
\text { Pathways }\end{array}$ & \begin{tabular}{c} 
Effect Size \\
\cline { 2 - 3 }
\end{tabular} & $\begin{array}{c}\text { SE } \\
\boldsymbol{\beta}\end{array}$ & $\begin{array}{c}\text { Bias-Corrected CI } \\
\mathbf{( 9 5 \% )}\end{array}$ \\
\hline $\mathrm{I} \rightarrow 3 \rightarrow 4$ & $-0.032^{*}$ & 0.018 & {$[-0.077,-0.002]$} \\
\hline $2 \rightarrow 3 \rightarrow 4$ & $-0.019^{*}$ & 0.013 & {$[-0.054,-0.00 \mathrm{I}]$} \\
\hline $\begin{array}{l}\text { Total indirect } \\
\text { effect }\end{array}$ & $-0.05 \mathrm{I}^{* *}$ & 0.027 & {$[-0.109,-0.003]$} \\
\hline
\end{tabular}

Notes: I. BII harmony; 2. National identity; 3. Power Values; 4. COVID-I9-related anxiety. $\mathrm{n}=235,{ }^{*} \mathrm{p}<0.05,{ }^{*} \mathrm{p}<0.01$.

negatively associated with COVID-19-related anxiety, respectively mediated. The mediating role of power values in those relationships was statistically negatively significant, suggesting that power values plays an inhibiting mediating role.

\section{Discussion}

This present research explored the relationships between bicultural harmony, national identity, and COVID-19 related anxiety, and tested whether power values mediated this relationship. The result found no difference in the levels of COVID-19 related anxiety between male and female. Which consistent with the results of previous studies, ${ }^{69}$ while inconsistent with previous studies. ${ }^{70}$ Social background and psychological factors may explain such differences. Our findings suggest a strong negative relationship between BII (cultural harmony/blendedness), national identity, and COVID-19-related anxiety. People higher in bicultural harmony and national identity had lower COVID-19related anxiety, and power values decreased COVID-19related anxiety among ethnic minority college students in China. BII-harmony plays a role in reducing COVID-19related anxiety. These results are in line with a previous study. $^{35}$ The positive relationship between BII-harmony and national identity is also consistent with the results of

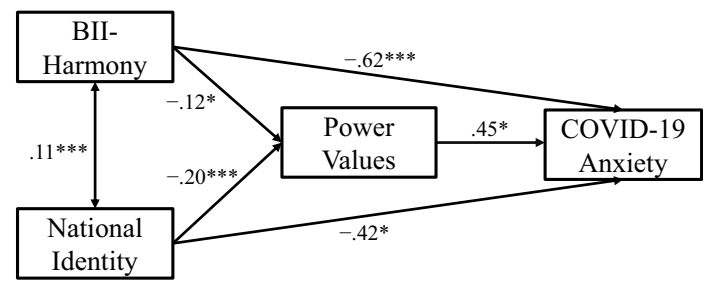

Figure I Model of BII-harmony, national identity on COVID-19-related anxiety. Non-significant demographic paths have been removed for ease of viewing. $n=235$, $*_{p}<0.05, * * * p<0.001$. previous studies. ${ }^{55,56}$ Our findings are in accord with those of earlier research that revealed that BII positively relates to multicultural persons' psychological adjustment (eg having lower levels of anxiety, with increased life satisfaction and self-esteem). ${ }^{42,71}$

National identity also plays a role in reducing COVID19-related anxiety. Similarly, the relationship between national identity and anxiety is also consistent with existing studies. ${ }^{48,63,72}$ National identity is a positively relevant variables in low levels of behavioral and emotional problems. ${ }^{56}$ Specifically, individuals who have formed a strong BII-harmony and national identity towards China tend to have more positive psychological resources to focus on reducing COVID-19-related anxiety. The implications of this study's findings need to be discussed. During the COVID-19 outbreak, people experienced limited mobility, with some being placed in isolation. This indicates that collectivists may derive a sense of lessened anxiety from collective identity in the face of difficulties that need collective effort.

As expected, power values also mediate the relationship between BII-harmony, national identity, and anxiety; this supports hypotheses 3-4. According to Schwartz's value theory, individualistic power values emphasize the control of material, social resources, and people, and promote personal interests by controlling what happens to minimize or avoid anxiety-provoking threats, as opposed to advocating universal values. Power values include the dominance, resources, and face subtypes. In terms of life goals, people who strongly emphasize "extrinsic" rather than "intrinsic" life goals are positively associated with higher anxiety. ${ }^{63}$ BII-harmony and national identity emphasize universalism with appreciation, understanding, tolerance, and protection of people's welfare. Therefore, power values play an inhibitory mediating effect in the relationship between BII-harmony, national identity, and COVID-19-related anxiety.

The present research suggests that the collective cultural identity in reaction to COVID-19-related anxiety was further affected by personal power values. The results emphasize the potential of BII-harmony, national identity, and power values in reducing anxiety during the COVID19 pandemic. Apart from shedding light on the effects of the current COVID-19 pandemic on a subset of the public, the relevance of the study lies in its cross-cultural and intercultural implications. The role of different cultural worldviews is an increasingly timely and an important topic given the fluidity of people and the ever-increasing 
migrations of people occasioned by wars and climate change. The negative effects of the COVID-19 crisis on people's lives is also of continuing interest, and findings that can inform programs to mitigate those effects are valuable.

\section{Limitations}

This study has some limitations. First, since our study recruited participants from Chinese ethnic groups, the universality of the results needs to be improved. Therefore, new studies with more diverse ethnic groups or national populations and at different stages of the COVID-19 crisis are needed to test the mediation model proposed in this study. Second, the mediating relationship requires a more exhaustive explanation in a more complex model. Nevertheless, future research should seek to replicate the reported effects in different contexts to obtain a better sense of their generalizability. Finally, as the data were collected online, the participants may not have provided accurate information, which may have affected the results of this study. The nature of cross-sectional data makes it impossible to infer the direction of the relationship, and the causal relationship between the study variables cannot be shown.

\section{Conclusion}

The novelty of the study lies in its interesting overlapping of cross-cultural aspects of COVID-19-related responses with intra-cultural aspects, since participants are ethnic minority Chinese students, in other words, there are shared cultural aspects as well as distinctive cultural aspects within an overarching setting (China). The interplay of bicultural integration versus nationalism, as well as the collectivism versus individualism dimension, is enlightening. The applicability of the findings across many intercultural settings is important.

Ethnic minority college students' BII-harmony and national identity were significantly negatively associated with COVID-19-related anxiety. Power values partially mediated the relationship between BII-harmony, national identity, and COVID-19-related anxiety. Our findings indicate that ethnic minority college students' BII-harmony and national identity could have the function of protecting them from COVID-19-related anxiety.

The study also highlights the importance of investigating the interaction effect between cultural identity, personal values, and personal feelings (COVID-19-related anxiety) during the COVID-19 outbreak. Finally, it presents the interesting possibility that during crises, a collectivist identity reduces anxiety and may encourage a more positive reaction.

In general, the potential role of collective identity (BII, national identity) in the current crisis response provides a further perspective. An emphasis on collective identity and a clear expression of "we are together" may be a fruitful effort to ease people's anxious responses to the epidemic, helping to reduce anxiety in this particular situation and during future crises. This study further reveals the potential role of cultural identity in emotional regulation during crisis.

\section{Data}

The datasets in the study are available from the corresponding author on reasonable request.

\section{Acknowledgments}

All authors have made substantial contributions to the research design, data collection, analysis and interpretation; participated in drafting and critically revising articles; agreed to submit to the current journal; approved the version to be published; and agreed to be responsible for all aspects of the research.

\section{Funding}

This research was supported by the MOE Project of Key Research Institute of Humanities and Social Sciences at Universities (15JJDZONGHE022), the Research Subject of Philosophy and Social Science in Guangxi Zhuang Autonomous Region (18FSH006), and the Theoretical and Practical Research on Education of College Students in Guangxi Zhuang Autonomous Region (2018LSZ031), China.

\section{Disclosure}

The authors report no conflicts of interest in this work.

\section{References}

1. Brooks SK, Webster RK, Smith LE, et al. The psychological impact of quarantine and how to reduce it: rapid review of the evidence. Lancet. 2020;395(10227):912-920. doi:10.1016/S0140-6736(20) 30460-8

2. Qiu J, Shen B, Zhao M, Wang Z, Xie B, Xu Y. A nationwide survey of psychological distress among Chinese people in the COVID-19 epidemic: implications and policy recommendations. Gen Psychiatry. 2020;33(2):e100213. doi:10.1136/gpsych-2020100213 
3. Robles-Bello MA, Sánchez-Teruel D, Naranjo NV. Variables protecting mental health in the Spanish population affected by the COVID-19 pandemic. Curr Psychol. 2020;1-12. doi:10.1007/ s12144-020-01132-1

4. Wang C, Pan R, Wan X, et al. Immediate psychological responses and associated factors during the initial stage of the 2019 Coronavirus Disease (COVID-19) epidemic among the general population in China. Int $J$ Environ Res Public Health. 2020;17(17295). doi:10.3390/ijerph17051729

5. Xiang Y, Yang Y, Li W, et al. Timely mental health care for the 2019 novel coronavirus outbreak is urgently needed. Lancet Psychiat. 2020;7(3):228-229. doi:10.1016/S2215-0366(20)30046-8

6. Wang Y, Di Y, Ye J, Wei W. Study on the public psychological states and its related factors during the outbreak of coronavirus disease 2019 (COVID-19) in some regions of China. Psychol Health Med. 2020;1-10. doi:10.1080/13548506.2020.1746817

7. Lai J, Ma S, Wang Y, et al. Factors associated with mental health outcomes among health care workers exposed to coronavirus disease 2019. JAMA Netw Open. 2020;3(3):e203976. doi:10.1001/ jamanetworkopen.2020.3976

8. Biddlestone M, Green R, Douglas KM. Cultural orientation, power, belief in conspiracy theories, and intentions to reduce the spread of COVID-19. Brit J Soc Psychol. 2020;59(3):663-673. doi:10.1111/ bjso. 12397

9. Zhao-liang AWWL. The stigmatization of people with mental illness as a stressor towards people suffering from mental illness in China. Philos Soc Sci. 2017.

10. Ji L, Khei M, Yap S, Wang X, Zhang Z, Hou Y. Cultural differences in the construal of suffering and the COVID-19 pandemic. Soc Psychol Pers Sci. 2020;194855062095880. doi:10.1177/ 1948550620958807

11. Jetten J, Postmes T, Mcauliffe BJ. 'We're all individuals': group norms of individualism and collectivism, levels of identification and identity threat. Eur J Soc Psychol. 2002;32(2):189-207. doi:10.1002/ ejsp.65

12. Douglas M. Risk and Blame: Essays in Cultural Theory. London, UK: Routeledge; 1994. doi:10.4324/9780203430866

13. Tajfel H, Turner JC. The social identity theory of inter-group behavior. Psy Intergroup Relat. 1986;13(3):7-24.

14. Phinney JS. Ethnic identity in adolescents and adults: review of research. Psychol Bull. 1990;108(3):499-514. doi:10.1037/00332909.108.3.499

15. Berry JW. Psychology of acculturation. Nebr Symp Motiv. 1989;37:201-234.

16. Umaña-Taylor AJ, Yazedjian A, Bámaca-Gómez M. Developing the ethnic identity scale using eriksonian and social identity perspectives. Identity. 2004;4(1):9-38. doi:10.1207/S1532706XID0401 2

17. Rivas-Drake D, Seaton EK, Markstrom C, et al. Ethnic and racial identity in adolescence: implications for psychosocial, academic, and health outcomes. Child Dev. 2014;85(1):40-57. doi:10.1111/cdev.12200

18. Aho KL, Liu JH. Indigenous suicide and colonization: the legacy of violence and the necessity of self-determination. Int J Conf Violence. 2010;4(1):124-133.

19. Bhui K, Stansfeld S, Head J, et al. Cultural identity, acculturation, and mental health among adolescents in east London's multiethnic community. J Epidemiol Community Health. 2005;59(4):296-302. doi:10.1136/jech.2003.014456

20. Brittian AS, Umana-Taylor AJ, Lee RM, et al. The moderating role of centrality on associations between ethnic identity affirmation and ethnic minority college students' mental health. $J$ Am Coll Health. 2013;61(3):133-140. doi:10.1080/07448481.2013.773904

21. Rogers-Sirin L, Gupta T. Cultural identity and mental health: differing trajectories among Asian and Latino youth. J Couns Psychol. 2012;59(4):555. doi:10.1037/a0029329
22. Atkinson DR, Gim RH. Asian-American cultural identity and attitudes toward mental health services. J Couns Psychol. 1989;36 (2):209-212. doi:10.1037/0022-0167.36.2.209

23. Kiang L, Yip T, Gonzales-Backen M, Witkow M, Fuligni AJ. Ethnic identity and the daily psychological well-being of adolescents from Mexican and Chinese backgrounds. Child Dev. 2006;77 (5):1338-1350. doi:10.1111/j.1467-8624.2006.00938.x

24. Smith TB, Silva L. Ethnic identity and personal well-being of people of color: a meta-analysis. J Couns Psychol. 2011;58(1):42-60. doi: $10.1037 / \mathrm{a} 0021528$

25. Umana A-Taylor AJ, Updegraff KA. Latino adolescents' mental health: exploring the interrelations among discrimination, ethnic identity, cultural orientation, self-esteem, and depressive symptoms. J Adolescence. 2007;30(4):549-567. doi:10.1016/j. adolescence.2006.08.002

26. Williams AD, Clark TC, Lewycka S. The associations between cultural identity and mental health outcomes for indigenous māori youth in New Zealand. Front Public Health. 2018;6. doi:10.3389/ fpubh.2018.00319.

27. Mandara J, Richards MH, Ragsdale GHL. The effects of changes in racial identity and self-esteem on changes in African American adolescents mental health. Child Dev. 2009;80(6):1660-1675. doi:10.1111/j.1467-8624.2009.01360.x

28. Yao J, Yang L. Perceived prejudice and the mental health of chinese ethnic minority college students: the chain mediating effect of ethnic identity and hope. Front Psychol. 2017;8:1167. doi:10.3389/ fpsyg.2017.01167

29. Richmond AH. Globalization: implications for immigrants and refugees. Ethn Racial Stud. 2002;25(5):707-727. doi:10.1080/ 0141987022000000231

30. Carballo M, Divino JJ, Zeric D. Migration and health in the European Union. Trop Med Int Health. 1998;3(12):936-944. doi:10.1046/ j.1365-3156.1998.00337.x

31. Ye Baojuan FX. The effects of cultural intelligence on minority preparatory undergraduates' subjective well-being: the chain mediating effect of bicultural identity integration and acculturative stress. J Gerontol B Psychol. 2017;40(04):892-897. doi:10.16187/j.cnki. issn1001-4918.2017.06.13

32. Benet-Martinez V, Haritatos J. Bicultural identity integration (BII): components and psychosocial antecedents. $J$ Pers. 2005;73 (4):1015-1050. doi:10.1111/j.1467-6494.2005.00337.x

33. Ferrari L, Rosnati R, Manzi C, Benet-Martinez V. Ethnic identity, bicultural identity integration, and psychological well-being among transracial adoptees: a longitudinal study. New Dir Child Adolesc Dev. 2015;2015(150):63-76. doi:10.1002/cad.20122

34. Huynh Q, Benet-Martínez V, Nguyen AD. Measuring variations in bicultural identity across U.S. ethnic and generational groups: development and validation of the bicultural identity integration scaleversion 2 (BIIS-2). Psychol Assess. 2018;30(12):1581-1596. doi:10.1037/pas0000606

35. Tikhonov AA, Espinosa A, Huynh Q, Anglin DM. Bicultural identity harmony and American identity are associated with positive mental health in U.S. racial and ethnic minority immigrants. Cultur Divers Ethnic Minor Psychol. 2019;25(4):494-504. doi:10.1037/cdp0000268

36. Kashima ES, Abu-Rayya HM. Longitudinal associations of cultural distance with psychological well-being among Australian immigrants from 49 countries. J Cross Cult Psychol. 2014;45(4):587-600. doi:10.1177/0022022113519857

37. Berry JW. "Immigrant youth in cultural transition: acculturation, identity, and adaptation across national contexts. “. Ztschrift Fur Padagogik. 2006;55(3):303-332. doi:10.1111/j.1464-0597.2006.00256.x

38. Huynh, Que Lam, A. M. D. Nguyen, and Verónica Benet-Martínez. Bicultural Identity Integration. Handbook of identity theory and research. 2011:827-842. doi:10.1007/978-1-4419-7988-9_35 
39. Nguyen AMD, Benet-Martinez V. Biculturalism and adjustment: a meta-analysis. $J$ Cross Cult Psychol. 2013;44(1):122-159. doi:10.1177/0022022111435097

40. Yampolsky MA, Amiot CE, de la Sablonnière R. The Multicultural Identity Integration Scale (MULTIIS): developing a comprehensive measure for configuring one's multiple cultural identities within the self. Cult Divers Ethn Min. 2016;22(2):166-184. doi:10.1037/ cdp0000043

41. Downie M, Mageau GA, Koestner R, Liodden T. On the risk of being a cultural chameleon: variations in collective self-esteem across social interactions. Cult Divers Ethn Min. 2006;12(3):527. doi:10.1037/1099-9809.12.3.527

42. Chen SX, Benet-Martínez V, Bond MH. Bicultural identity, bilingualism, and psychological adjustment in multicultural societies: immigration-based and globalization-based acculturation. $J$ Pers. 2008;76(4):803-838. doi:10.1111/j.1467-6494.2008.00505.x

43. Jean S, Horenczyk G, Liebkind K, et al. Ethnic identity, immigration, and well-being: an interactional perspective. J Soc Issues. 2001. doi:10.1111/0022-4537.00225

44. Cokley K. Critical issues in the measurement of ethnic and racial identity: a referendum on the state of the field. J Couns Psychol. 2007;54(3):224-234. doi:10.1037/0022-0167.54.3.224

45. David O, Bar-Tal D. A sociopsychological conception of collective identity: the case of national identity as an example. Pers Soc Psychol Rev. 2009;13(4):354. doi:10.1177/1088868309344412

46. Owell TEF, Ong AD, Phinney JS. National identity and perceived discrimination predict changes in ethnic identity commitment: evidence from a longitudinal study of Latino college students. Appl Psychol. 2013;62(3):406-426. doi:10.1111/j.1464-0597.2012.00486.x

47. Berry JW, Phinney JS, Sam DL, Vedder P. Immigrant youth: acculturation, identity, and adaptation. Appl Psychol. 2010;55(3). doi:10.1111/j.1464-0597.2006.00256.x

48. Oliveira Lima ME, Da Silva P, Carvalho NC, Monteiro Farias LC. Identidade nacional e confiança nas instituições em contexto de crise no Brasil. Psicologia e Saber Social. 2018;6(2). doi:10.12957/psi. saber.soc.2017.33557

49. Gupta T, Rogers-Sirin L, Okazaki S, Ryce P, Sirin SR. The role of collective self-esteem on anxious-depressed symptoms for Asian and Latino children of immigrants. Cult Divers Ethn Min. 2014;20 (2):220-230. doi:10.1037/a0035022

50. Lee RM. Resilience against discrimination: ethnic identity and other-group orientation as protective factors for Korean Americans. J Couns Psychol. 2005;52(1):36-44. doi:10.1037/0022-0167.52.1.36

51. Long Y, Zhu SH, Quan FY, Yang YL, Zheng Y. The impact of ethnic affirmation and belonging on other-group orientation: the mediating role of personality traits and values in different ethnic groups. Pers Indiv Differ. 2020;152:109574. doi:10.1016/j.paid.2019.109574

52. Ponterotto JG, Park-Taylor J. Racial and ethnic identity theory, measurement, and research in counseling psychology: present status and future directions. $J$ Couns Psychol. 2007;54(3):282-294. doi: $10.1037 / 0022-0167.54 .3 .282$

53. Tummala-Narra P. Ethnic identity, perceived support, and depressive symptoms among racial minority immigrant-origin adolescents. Am J Orthopsychiatry. 2015;85(1):23-33. doi:10.1037/ort0000022

54. Espinosa A, Tikhonov A, Ellman LM, Kern DM, Lui F, Anglin D. Ethnic identity and perceived stress among ethnically diverse immigrants. J Immigr Minor Health. 2016. doi:10.1007/s10903016-0494-z
55. Huynh QL Variations in biculturalism: measurement, validity, mental and physical health correlates, and group differences. Dissertations \& Theses - Gradworks; 2009

56. Manzi C, Ferrari L, Rosnati R, Benet-Martinez V. Bicultural identity integration of transracial adolescent adoptees: antecedents and outcomes. J Cross Cult Psychol. 2014;45(6):888-904. doi:10.1177/ 0022022114530495

57. Sheng-Hua JIN. The structure and characteristics of contemporary chinese values. Xin Li Xue Bao. 2009;41(10):1000-1014. doi:10.3724/SP.J.1041.2009.01000.

58. Bilsky W, Schwartz SH. Measuring motivations: integrating content and method. Pers Indiv Differ. 2008;44(8):1738-1751. doi:10.1016/j. paid.2008.02.001

59. Jenkins S, Reysen S, Katzarska-Miller I. Ingroup identification and personality. J Interpers Relat Intergr Relat Iden. 2012;5:9-16.

60. Schwartz SH. Universals in the content and structure of values: theoretical advances and empirical tests in 20 countries. Adv Exp Soc Psychol. 1992;5:1-65. doi:10.1016/s0065-2601(08)60281-6

61. Schwartz SH, Cieciuch J, Vecchione M, et al. Refining the theory of basic individual values. J Pers Soc Psychol. 2012;103(4):663-688. doi:10.1037/a0029393

62. Bilican IF, Yapici A, Kutlu OM. A value model for depressive symptoms and hopelessness among university students in Turkey. Edu Sci. 2016. doi:10.12738/estp.2016.4.0112

63. Sagiv L, Schwartz SH. Value priorities and subjective well-being: direct relations and congruity effects. Eur J Soc Psychol. 2000;30 (2):177-198. doi:10.1002/(SICI)1099-0992(200003/04)30:2<177:: AID-EJSP982>3.0.CO;2-Z

64. Sapienza I, Hichy Z, Guarnera M, Nuovo SD. Effects of basic human values on host community acculturation orientations. Int $J$ Psychol. 2010;45(4):311-319. doi:10.1080/00207591003587978

65. Roccas S, Schwartz SH, Amit A. Personal value priorities and national identification. Polit Psychol. 2010;31(3):393-419. doi:10.1111/j.1467-9221.2010.00763.x

66. Xiaoli Y, Hongli Y, Li L, Psychology SO, University NN. The relationship between bicultural identity integration and psychological adaptation: the mediating role of dialectical self. J Psy Sci. 2015. doi:10.16719/j.cnki.1671-6981.20150628

67. Qin X. The development of ethnic identity in 11 to 20 years old Chinese adolescents [dissertation]. Shanghai: Central China Normal University; 2005. doi: 10.7666/d.y729998.

68. Killgore WDS, Taylor EC, Cloonan SA, Dailey NS. Psychological resilience during the COVID-19 lockdown. Psychiat Res. 2020;291:113216. doi:10.1016/j.psychres.2020.113216

69. Cao W, Fang Z, Hou G, Han M, Zheng J. The psychological impact of the COVID-19 epidemic on college students in China. Psychiat Res. 2020;287:112934. doi:10.1016/j.psychres.2020.112934

70. Sánchez-Teruel D, Robles-Bello MA, Valencia-Naranjo N. Do psychological strengths protect college students confined by COVID-19 to emotional distress? The role of gender. Pers Indiv Differ. 2020. doi:10.1016/j.paid.2020.110507

71. Ferrari L, Rosnati R, Manzi C. Ethnic identity, bicultural identity integration, and psychological well-being among transracial adoptees: a longitudinal study. New Dir Child Adolesc. 2015;2015(150). doi:10.1002/cad.20122

72. Chen SX, Benet-Martínez V, Wu WCH, Lam BCP, Bond MH. The role of dialectical self and bicultural identity integration in psychological adjustment. J Pers. 2013;81(1):61-75. doi:10.1111/j.14676494.2012.00791.x 


\section{Publish your work in this journal}

Psychology Research and Behavior Management is an international, peer-reviewed, open access journal focusing on the science of psychology and its application in behavior management to develop improved outcomes in the clinical, educational, sports and business arenas. Specific topics covered in the journal include: Neuroscience, memory and decision making; Behavior modification and management; Clinical applications; Business and sports performance management; Social and developmental studies; Animal studies. The manuscript management system is completely online and includes a very quick and fair peer-review system, which is all easy to use. Visit http://www. dovepress.com/testimonials.php to read real quotes from published authors. 